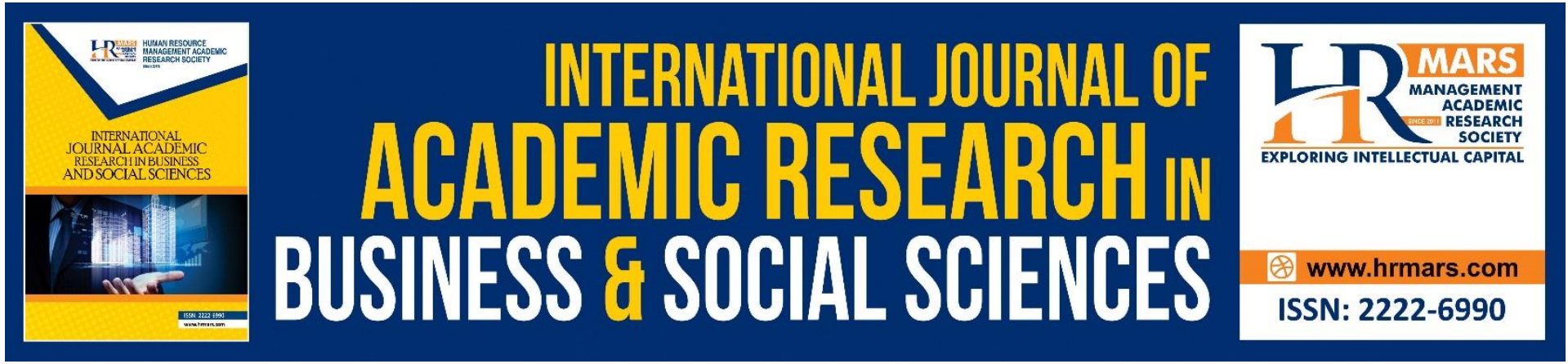

\title{
A Review of Human Resources Development Research in the Background of High-quality Economic Development in China
}

\section{XU Xianhang, Mohd Anuar Arshad, Arshad Mahmood}

To Link this Article: http://dx.doi.org/10.6007/IJARBSS/v11-i7/10361

DOI:10.6007/IJARBSS/v11-i7/10361

Received: 11 May 2021, Revised: 14 June 2021, Accepted: 05 July 2021

Published Online: 24 July 2021

In-Text Citation: (Xu et al., 2021)

To Cite this Article: Xu, Xianhang., Arshad, M. A., \& Mahmood, A. (2021). A Review of Human Resources Development Research in the Background of High-quality Economic Development in China. International Journal of Academic Research in Business and Social Sciences, 11(7), 1126-1137.

Copyright: (c) 2021 The Author(s)

Published by Human Resource Management Academic Research Society (www.hrmars.com)

This article is published under the Creative Commons Attribution (CC BY 4.0) license. Anyone may reproduce, distribute, translate and create derivative works of this article (for both commercial and non-commercial purposes), subject to full attribution to the original publication and authors. The full terms of this license may be seen at: http://creativecommons.org/licences/by/4.0/legalcode

Vol. 11, No. 7, 2021, Pg. 1126 - 1137

Full Terms \& Conditions of access and use can be found at http://hrmars.com/index.php/pages/detail/publication-ethics 


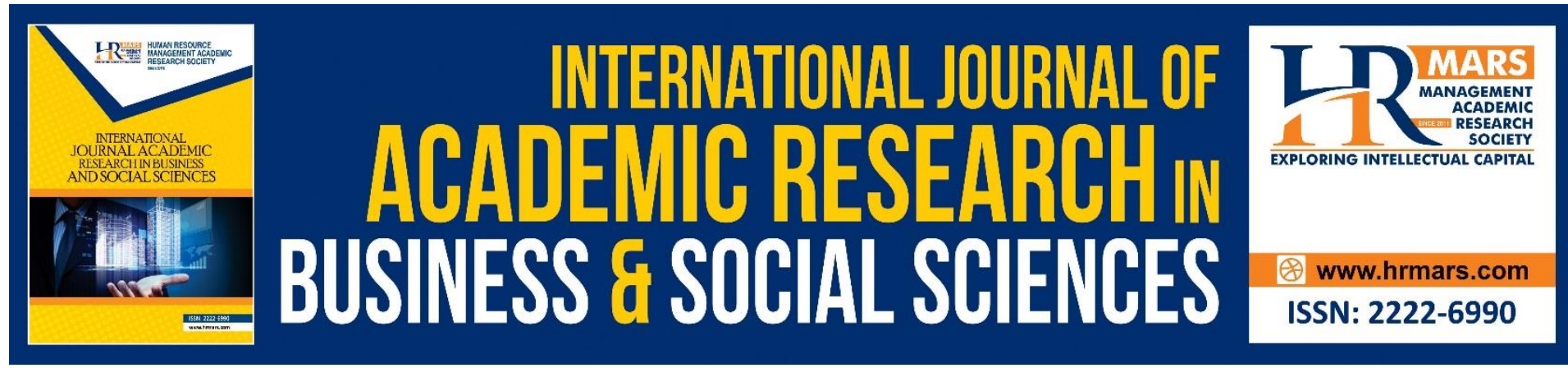

\title{
A Review of Human Resources Development Research in the Background of High-quality Economic Development in China
}

\author{
XU Xianhang
}

School of Management, Universiti Sains Malaysia, Gelugor 11800, Penang, Malaysia School of Innovation and Entrepreneurship, Chongqing Institute of Engineering, 400056

Chongqing, China

Mohd Anuar Arshad

School of Management, Universiti Sains Malaysia, Gelugor 11800, Penang, Malaysia

\section{Arshad Mahmood}

School of Business and Economics, University of Wuppertal, 42119 Wuppertal, Germany

Email: anuar_arshad@usm.my

\begin{abstract}
The economic strength of a country or region is closely related to the use level of its human resources. China's economy has shifted from a high-speed development stage to a highquality development. To achieve high-quality economic development in China, human resource development is essential. Human resource development has special significance for China. By reviewing the concept of human resource development, human resource development in the context of high-quality development and other related research results, we can find that scholars have studied the connotation of human resource development from different perspectives, and research on human resource development strategies from the macro and medium levels. Some progress has also been made, and the theoretical system in the field of human resource development has been improved to a certain extent, but the research direction is not focused enough. Compared with the fast-developing practice of human resource development, theoretical research appears to be lagging. Combining literature review and China's national conditions, the following prospects are put forward for future research: By further expanding the connotation and theoretical framework of human resource development, introducing more effective measurement methods to improve the national and industrial human resource development strategy theory, and verifying that highquality development theories are in guidance at the macro and meso levels.
\end{abstract}

Keywords: High-quality Development, Human Resource Development, Human Capital 


\section{Introduction}

In the era of knowledge economy, innovation has gradually become the source of economic growth. Human resources are the most active factor in innovation activities. The level of development and utilization of human resources is closely related to the economic development of a country. It has been regarded by more and more countries as the key to determining overall national strength. At present, China's economy has shifted to a stage of high-quality development, and to achieve high-quality development, human resource development is crucial. How to grasp the core of talents and discuss the development of human resources under the background of high-quality development has special significance for China. Only by deeply understanding the connotation of human resource development under the new situation can we further tap the potential of human capital, continue to promote the strategy of strengthening the country with talents, and improve the quality and efficiency of industrial development, so as to achieve overall economic and social prosperity. In view of this, in order to deeply understand the connotation of human resource development and further play its role in promoting the economy and industry, this article is based on the background of high-quality development, from the concept of human resource development, human capital and economic growth, human capital and industrial transformation and upgrading, National and industrial human resource development strategies, etc., comment on relevant research in recent years, and combine the research prospects of China's national conditions, hoping to inspire future related research through this article.

\section{The Concept of Human Resource Development}

The research of human resource development emerged in the 1960s and 1970s. Harbison and Myers (1964) first put forward the term human resource development. They regarded it as a process to improve the knowledge, skills, and abilities of all people in the society, and described it as the accumulation of human capital and effective investment in economic development from the perspective of economics. Subsequently, Nadler (1970) systematically proposed a framework for human resource development, which defined human resource development as the process of purposeful development of the whole person, body, mind, and spirit, including both organizational activities and individual active learning. Since then, the theory of human resource development has gradually been accepted by the scholars. Many scholars have expounded the concept of human resource development from the perspectives of purpose, means and level.

\section{(1) The perspective based on purpose}

The concept of human resource development from the perspective of purpose mainly includes the following two kinds: one is to improve the value of human capital through investment. Craig (1976) proposed that human resource development aims to develop human potential through all aspects of lifelong learning. Xiao (1994) proposed that it is a process of the development and utilization of various human factors in groups or individuals. Second, it serves for the common development of individuals and organizations. Nadler and Wiggs (1986) proposed that it is an organized learning activity in a certain period, the purpose is to promote personal growth and improve organizational performance. Gilley (1989) proposed that it is a learning activity that promotes employee growth and work improvement within an organization, which helps to improve work performance and achieve organizational development. Stead and Lee (1996) proposed that it is a comprehensive social learning 
process. Jon and Randy (2006) proposed that it is a series of self-learning and performance improvement activities that drive business performance.

\section{(2) From the Perspective of Means}

As for the means of human resources development, they mainly include training, continuing education, learning, physical and mental health care, recreational and sports activities, planning, utilization, etc. Pan (1991) believed that human resource development is a process of continuously improving personnel quality and capability through various ways and realizing reasonable personnel allocation. Swanson (2001) proposed that it is a process of improving employee skills and realizing employee self-growth through training, independent learning, and organizational construction. Lu (2001) believes that it is a series of measures and means to rationally excavate and utilize various resources and improve the utilization of human resources, including education, training, allocation, etc. Liu (2017) proposed that developers utilize human resources by means of learning, training, and control. Schaupp (2021) pointed out that human resource development needs to cooperate with human resource development practitioners and other organizational actors, especially those who need to master production changes, to focus on developing new human resource development solutions.

\section{(3) Based on the Perspective of Hierarchy}

According to the subject and content of human resource development, it can be divided into three levels: macro, meso and micro. Most of the concepts expounded by early scholars are related to individual ability cultivation and enterprise performance improvement activities, which belong to the category of micro human resource development. With the rapid development of economy and society, the government, as a national or regional management organization, begins to pay attention to the rational allocation of human resources. Scholars have also expanded the concept of human resource development to the macro and meso levels. Divided human resource development into micro human resource individual development and macro human resource group development. Wilson (2013) defined human resource development as the process of improving the cognitive, emotional, and behavioral capabilities of all people and organizations in society. Reed (2017) proposed that human resource development includes applied learning at individual, organizational and government levels to improve human resource capabilities in different functional areas.

\section{Human Resource Development under the Background of high-quality Development}

Since the 19th National Congress of the Communist Party of China (CPC), Chinese scholars have deepened their research on high-quality development. The connotation of high-quality development, the macro level refers to stable economic growth, the meso level refers to the continuous realization of industrial transformation and upgrading and layout optimization, and the micro enterprise level includes first-class competitiveness, continuous innovation, and brand influence (Zhao et al., 2019). In view of the micro level of human resource development activities have been widely used in personal self-improvement and enterprise human resource management practices, the study of human resource development from the macro and meso levels has more theoretical and practical significance. Human capital is the research tool and theoretical basis of human resource development (Xiao and Rao, 2006), guiding the formulation and implementation of national and industrial human resource development strategies. Combined with the development of high-quality connotation, this 
article will research development under the background of high-quality human resources development due to explore human capital and economic growth, national strategy for human resources development, human capital and industrial transformation and upgrading, industrial content such as human resources development strategy, namely the basic theory of macro and micro level and development strategy.

\section{(1) Human Capital and Economic Growth}

Scholars' research on human capital and economic growth can be roughly divided into three stages. The first stage is the initial stage. Schultz (1961) took the lead in putting forward the concept of human capital due to his research on economic growth and initiated the practical application of human capital theory in human resource development. Since then, the theory of human capital has gradually merged into the mainstream of the West. The second stage is the development stage. The endogenous growth model proposed by Romer (1986) broke the limitations of the exogenous economic growth model of neoclassical economics, confirmed the relationship between human capital and sustained economic growth, and pointed out the important position and 'engine' role of human resources in economic growth (Lucas and Robert, 1988). Since then, many scholars have used the production function model for reference to analyze and verify the relationship between human capital and economic growth in different countries or regions. Krueger et al. (2001); Hu (2003); Vandenbussche et al (2006); Huang et al (2009); Fleisher et al (2009); Du et al (2014) respectively measured the contribution of human capital to technological progress and economic growth in China, the United States, the United Kingdom and Japan, and all confirmed that there is an obvious relationship between economic growth and human capital. The third stage is the innovation stage. In recent years, some scholars began to introduce new models and new variables when studying the relationship between human capital and economic growth. Lu and Su (2017) adopted additive model, Ogundari and Awokuse (2018) adopted systematic generalized moment method (SGMM) to verify the positive impact of human capital on economic growth. Based on the endogenous growth model, Liang and Zhang (2016) introduced the technological innovation variable and An and Lei (2019) introduced the carbon emission variable to analyze the relationship among human capital, economic growth and new variables respectively.

\section{(2) Human Capital and Industrial Transformation and Upgrading}

Industrial upgrading is a process of shifting industries to more profitable or technologically advanced sectors of the economy to improve the competitiveness of the economy (Gereffi, 1999). With the deepening of the third industrial revolution and the development of human resources management, the factors affecting the foreign and domestic research on industrial transformation and upgrading, began to focus on human capital, combined with industrial upgrading the study of human resource development is gradually increased, roughly divided into two directions: one is the use of model validation compatibility of human capital and industrial upgrading. Guan et al (2011) used Minter model, Tang (2014) used mathematical model, Ahmeti (2015) used operational fitness model, and Ma (2015) used quantile regression and counterfactual decomposition method to verify the fit degree of human capital and industrial transformation and upgrading in different regions. The second is to use the model to quantitatively analyze the influence and contribution of human capital. Rasa et al. (2016) respectively measured the impact and contribution of human capital in different regions with the help of Granger causality test model, Zheng (2017) with the help of Getis spatial filtering 
model, Chen et al (2019) with the help of spatial Dubin model and Harris et al. (2019) with the help of human capital behavior model, and all found that there is a continuous positive effect on industrial transformation and upgrading. The increase of labor cost can promote the enterprise to develop the productivity of the employees instead of reducing the employees, thus promoting the technological progress and industrial upgrading of the enterprise (Riley et al., 2017). The first type of research is more focused on verifying the significant degree of the relationship between human capital and industrial transformation and upgrading, without indepth study of their internal connection. The second type of research strengthens the analysis of influencing factors and contributions, making up for the deficiency of the first type of research to a certain extent.

\section{(3) National Human Resources Development Strategy}

The early human resource development strategies are mostly formulated for the development of a single organization or individual, which is a micro human resource development strategy. After Romer and Lucas put forward the 'New Growth Theory' in the 1980 s, many empirical studies proved that human capital was the source of economic growth, and the benefits of macro human resource development were gradually reflected (Wilson, 2013). In recent years, some developed countries have begun to make scientific plans for human resource development and have formulated human resource development strategies at the national or regional level, such as the United Kingdom Talent Development Strategy, the United States Scientific and Technological Talent Strategic Plan, the German High-tech Talent Strategy and the Canadian Global Talent Plan. Scholars also began to study HRD strategies based on the national level. For example, Kuchinke (2003) and Quintanilla (2009) proposed the national HRD strategies of the UK and Spain respectively. These programs and studies have greatly promoted the social development and economic take-off of developed countries. The research on national human resource development in China is a little later than that in western developed countries. In 1990, the former Talent Research Institute of the Ministry of Personnel, together with more than 10 ministries and commissions, organized a seminar on China's human resources development strategy, which opened the prelude to the study of national human resources development strategy (Lu, 2001). Later, Zhu et al. (1992), Zhao (1996); Xiao and Rao (2006) studied the national human resource development strategy from the perspectives of development and utilization, experience reference and policy formulation in combination with China's national conditions. In recent years, with the indepth promotion of China's rural revitalization strategy and 'the Belt and Road' initiative, the research on rural and 'the Belt and Road' areas of human resource development strategy has been gradually enriched. Wang et al (2018) proposed how to deploy the human resource development strategy in the 'the Belt and Road' economic belt. Yang (2019) proposed that the rural human resources development strategy should cover moral and mental abilities, skills, health, physical fitness, and other contents. Huang (2020) analyzed the current obstacles to the development of human resources in rural areas in China, and proposed from the government level how to improve the rate of return of human capital investment in rural areas. Xiao, et al (2020) proposed to develop rural human resources by flexibly introducing professional talents, encouraging migrant workers to return to their hometowns for employment and entrepreneurship, relocating enterprises to rural areas, emphasizing the training and development of women groups, and improving the level of education and culture. Zhao, et al (2021) proposed ways to introduce, cultivate and use talents in human resource development of China's Hainan Free Trade Port from the aspects of establishing 
human resource service industrial park, increasing investment in education, formulating policies and systems, and strengthening the cooperation between government and enterprises. Although the research on national human resources development strategy by scholars has not been systematic, the relevant research results also provide a reference path for the implementation of China's talent development strategy.

\section{(4) Industrial human resources development strategy}

In the past 10 years, with the accelerated rise of China, India and other developing countries, scholars have gradually paid more attention to the emerging economies, and the research on human resource development strategy has also gone deep into the industrial level, focusing on the emerging industries in developing countries. According to different research methods, it can be roughly divided into two categories: one is qualitative research, mainly based on the status quo, characteristics, and problems. Xiong and Ge (2010), based on the analysis of the current situation and existing problems of human resources development in China's strategic emerging industries, proposed to develop scientific and technological human resources from the aspects of optimizing the talent structure and deepening the cooperation of 'industryuniversity-research'. Gu (2013), based on the analysis of talent demand characteristics in the process of service outsourcing industry upgrading in Zhejiang, proposed to formulate human resource development strategies in service outsourcing industry from the aspects of academic education, training, and overseas talent introduction. The other is quantitative research, with the help of mathematical models for empirical analysis. Based on the software industry in Indonesia, Aryanto (2015) discussed the positive relationship between the practice of human resource development strategy and innovation performance. Jain et al (2018), after conducting an empirical study on Bharti Telecom, the largest operator in India, put forward a human resource development strategy for the Indian telecom industry from aspects of work and life quality and welfare measures, organizational development, training and development, participatory management, performance management and rewards. Agus and Yosephine (2018) put forward a strategic model of human resource development in India's batik industry through analysis with the help of soft system method. Li et al. (2018) predicted the human resource demand of strategic emerging industries in Shanxi with the help of GBPBagging model and put forward development strategies such as improving the introduction mechanism, controlling the quality of talents and strengthening the exchange of talents. $\mathrm{Xu}$, X. H. (2021) proposed a human resource development strategy for the smart industry in terms of accelerating industrial development and promoting the industrial talent ecosystem based on the perspective of industrial transformation and upgrading.

\section{Summary and Outlook}

This article sorts out the concept of human resource development and human resource development in the context of high-quality development. Through the above research review, we can see that scholars have conducted long-term research on the connotation of human resource development from different perspectives. The scope of the concept definition has been continuously expanded, and a preliminary theoretical system has been formed. Some progress has also been made in the research on human resource development strategies at the macro and meso levels. The macro level uses various measurement models to verify and measure the relationship and influence between human capital and economic growth. The meso level also combines the effects of different industries on human capital. A qualitative and quantitative analysis was carried out with industrial transformation and upgrading. In 
general, the existing research has improved the theoretical system of human resource development to some extent, but the research direction is not focused enough and there is no widely accepted school of theory. Compared with the rapidly developing practice of human resource development, the theoretical research is lagging. Therefore, scholars need to continue to explore and pay attention to the following aspects.

(1) Expand the connotation and theoretical framework of human resource development. At present, scholars' exposition of its connotation is mainly from the perspectives of purpose, means and level, etc. Most of them are based on a certain level of macro, meso and micro. The contents of the exposition are also different, and a comprehensive and consistent view has not been formed yet. Future research can be considered from the perspective of synergy between the macro, the micro, and the micro level, combined with the high-quality development strategy of China's economy, further enrich the connotation of human resource development, and propose a relatively complete theoretical framework.

(2) Combining China's national conditions to improve the theoretical basis of the macro level and national human resources development strategy theory. Until today, developed countries are still innovating constantly, insisting on the implementation of human resource development as an important national strategy. Most of China's current studies are based on foreign endogenous growth models, which are not fully combined with China's national conditions and are of little practical guiding significance. Future research, can be in draw lessons from foreign theoretical model on the basis of carefully analyzing the unique system and culture of China, through the analysis of the theoretical model validation and further improve the human capital's relationship with China's economic growth, combined with China's social environment and economic development put forward the policy recommendations, formed with Chinese characteristics and practical guiding significance to the national human resources development strategy, provide theoretical support for the strategy of reinvigorating China through human resource development.

(3) Explore the theoretical basis and industrial human resources development strategy of the meso level. At present, the research results on the macro and micro levels have been enriched day by day, but the attention on the meso industry level is obviously less, and the research objects are mostly concentrated in emerging industries, and there is still a certain gap between establishing a relatively complete theoretical system. In the future research, firstly, the research object can be extended to more industries, the influence of human capital on industrial transformation and upgrading can be comprehensively analyzed, and the analysis framework of influencing factors of human resource development strategy can be further expanded. Second, combine the theory of high-quality development with the strategy of industrial transformation and upgrading, introduce more effective measurement methods or means, strengthen the research on industrial human resources development strategy from the quantitative point of view, and verify the guiding role of high-quality development theory in the meso level.

\section{Funding Statement}

Supported by Humanistic and Social Science Research Program of Chongqing Municipal Education Commission (Grant No. 20SKGH276) and Scientific and Technological Research Program of Chongqing Municipal Education Commission (Grant No. KJQN201901902) 


\section{Corresponding Author}

Mohd Anuar Arshad

School of Management, Universiti Sains Malaysia, Gelugor 11800, Penang, Malaysia

Email: anuar_arshad@usm.my

\section{References}

Harbison, F., Myers, C. A. (1964). Education, Manpower, and Economic Growth: Strategies of Human Resource Development. New York: McGraw-Hill.

Nadler, L. (1970). Developing Human Resources. Huston TX: Gulf Publishing.

Craig, R. L. (1976). Training and Development Handbook: A Guide to Human Resources Development. New York: McGraw-Hill.

Xiao, M. Z. (1994). Systematic Thinking on Human Resources Development[J]. China Human Resources Development, 6, 15-20. Doi: 10.16471/j.cnki.11-2822/c.1994.06.004

Nadler, L., Wiggs, G. D. (1986). Managing Human Resource Development. San Francisco: Jossey-Bass Publishers.

Gilley, J. W., Eggkand, S. A. (1989). Principles of Human Resource Development. New Jersey: Addison Wesley.

Stead, V., Lee, M. (1996). Human Resource Development: Perspectives, Strategies and Practice. London: Prentice Hall.

Jon, M. W., Randy, L. (2006). DeSimone. Human Resource Development. Boston: Cengage Learning.

Pan, J. Y. (1991). China's First Resource: Theory and Practice of Human Resources Development and Utilization. Beijing: Machinery Industry Press.

Swanson, R. A. (2001). Foundations of Human Resource Development. San Francisco: Berrett Koehler Publishers.

Lu, J. (2001). Comparison of human resource development strategies between China and foreign countries and its reference. Economic Science, (1), 102-110. Doi: 10.19523/j.jjkx.2001.01.013

Liu, T. M. (2017). China's human resource development strategy and policy. Xiangtan: Xiangtan University Press.

Wilson, J. P. (2013). International Human Resource Development: Learning; Education and Training for Individuals and Organisations. Human Resource Development Quarterly, 24(4), 561-566. Doi: 10.1002/hrdq.21174

Reed, S. M. HRCI. (2017). Human Resource Development. The HRCI Official Body of Knowledge. New Jersey: John Wiley \& Sons, Inc.

Zhao, J. B., Shi, D., Deng, Z. (2019). Research on the connotation of high-quality development. Economics and Management Research, (11), 15-31. Doi: 10.13502/j.cnki.issn10007636.2019.11.002

Schultz, T. W. (1961). Investment in Human Capital. The American Economic Review, 51, 1-17. https://www.academia.edu/37839955

Romer, P. M. (1986). Increasing Returns and Long-Run Growth. Journal of Political Economy, 94(5), 1002-1037. https://www.jstor.org/stable/1833190

Lucas, J., Robert, E. (1988). On the Mechanics of Economic Development. Journal of Monetary Economics, 22(1), 3-42. Doi: 10.1016/0304-3932(88)90168-7

Krueger, A. B., Mikael, L. (2001). Education for Growth: Why and for Whom?. Journal of Economic Literature, 39(4), 1101-1136. Doi: 10.2139/ssrn.223589 
Vandenbussche, J., Aghion, P., Meghir, C. (2006). Growth, Distance to Frontier and Composition of Human Capital. Journal of Economic Growth, 11(2), 97-127. Doi: 10.1007/s10887-006-9002-y

Fleisher, B., Li H Z., Zhao M. Q. (2009). Human Capital, Economic Growth, and Regional Inequality in China. Journal of Development Economics, 92(2), 215-231. Doi: 10.1016/j.jdeveco.2009.01.010

Jan, C., Ludmila, P., Dagmar, B. (2014). Human Capital, Economic Structure and Growth. Procedia Economics and Finance, 12, 5-92. Doi: 10.1016/S2212-5671(14)00323-2

Elena, P. (2015). The Impact of Human Capital on Economic Growth. Procedia Economics and Finance, 22, 184-190. Doi: 10.1016/S2212-5671(15)00258-0

Ogundari, K., Awokuse, T. (2018). Human Capital Contribution to Economic Growth in SubSaharan Africa: Does Health Status Matter More than Education?. Economic Analysis and Policy, 58, 131-140. Doi: 10.1016/j.eap.2018.02.001

Wang, J. Y. (2001). A comparative study on the role of human capital investment in economic growth between China and India. Education and Economy, 2, 55-58. Doi: CNKI:SUN:JYJI.0.2001-02-013.

Hu, Y. Y. (2003). Human Capital and Economic Growth: An Empirical Analysis. Economic Science, 1, 54-60. Doi: 10.19523/j.jjkx.2003.01.007

Yang, J., Zhang, Z. Y., Li, X. Y. (2005). Income distribution, human capital and economic growth: experience from China (1995-2003). Economic Science, 5, 5-15. Doi: 10.19523/j.jjkx.2005.05.001

Huang, J. B., Xie, L., Zhong, M. R. (2009). An Empirical Study on the Relationship between Innovative Human Capital and Economic Growth in my country. Science and Technology Progress and Policy, 1, 1-4. Doi: CNKI:SUN:KJJB.0.2009-01-005.

Du, W., Yang, Z. J., Xia, G. P. (2014). Research on the Mechanism of Human Capital Promoting Economic Growth. China Soft Science, 8, 173-183. Doi: CNKI:SUN:ZGRK.0.2014-08-018.

Lu, J., Su, Y. (2017). Human capital, economic growth and regional economic development differences: an empirical study based on a semiparametric additive model. Journal of Demography, 39(1), 89-101. Doi: 10.16405/j.cnki.1004-129X.2017.01.009

Hu, H. Y., Yao, C. (2018). Agglomeration economy, human capital and economic growth--A systematic GMM analysis based on provincial dynamic panel data. Industrial Technology Economy, 37(4), 106-113. Doi: CNKI:SUN:GHZJ.0.2018-04-014.

Liang, S. L., Zhang, L. J. (2016). Human Capital, Technological Innovation and Long-term Economic Growth--Based on the Analysis of Western my country. Technoeconomics and Management Research, 11, 29-34. Doi: CNKI:SUN:JXJG.0.2016-11-006.

An, C., Lei, M. (2019). Research on Carbon Dioxide Emissions, Human Capital and Endogenous Economic Growth. Chinese Management Science, 27(5), 149-160. Doi: 10.16381/j.cnki.issn1003-207x.2019.05.016

Gereffi. (1999). International Trade and Industrial Upgrading in the Apparel Commodity Chain. Journal of International Economics, 48, 37-70. Doi: 10.1016/S0022-1996(98)00075-0

Ardichvili, A., Gasparishvili, A. (2001). Human Resource Development in an Industry in Transition: the Case of the Russian Banking Sector. Human Resource Development International, 4(1), 47-63. Doi: 10.1080/13678860122157

Hausmann, R., Jason, H., Dani, R. (2007). What You Export Matters. Journal of Economic Growth, 12(1), 1-25. Doi: 10.1007/s10887-006-9009-4 
Ahmeti, F. (2015). Human Resources Development and Challenges Faced During Transition in Developing Economies. Social Science Electronic Publishing, 3(4), 1-17. https://www.academia.edu/13273006

Rasa, A., Viktorija, S., Simona, S. (2016). The Role of Human Capital for National Innovation Capability in Eu Countries. Economics and Culture, 13(1), 114-125. DOI: 10.1515/jec2016-0014

Riley, R., Bondibene, C. R. (2017). Raising the Standard: Minimum Wages and Firm Productivity. Labour Economics, 44, 27-50. Doi: 10.1016/j.labeco.2016.11.010

Harris, C. M., Wright, P. M., Mcmahan, G. C. (2019). The Emergence of Human Capital: Roles of Social Capital and Coordination that Drive Unit Performance. Human resource management journal, 29(2), 162-180. Doi: 10.1111/1748-8583.12212

Guan, H. P., Chen, X. M. (2011). Analysis of the interaction mechanism between industrial upgrading and human capital in the Pearl River Delta: Micro-evidence based on Dongguan. Journal of South China Normal University (Social Science Edition), 5, 95-102, 160. Doi: CNKI:SUN:HNSB.0.2011-05-021.

Tang, H. L. (2014). Research on Human Capital Structure, Technology Capital Allocation Structure and Industrial Transformation and Upgrading Capability. Statistics and Decision, 2, 106-108. DOI: 10.13546/j.cnki.tjyjc.000085

$\mathrm{Ma}, \mathrm{X}$. Q. (2015). Research on the fit of human capital and industrial transformation and upgrading under the new normal. China Human Resources Development, 3, 70-76. Doi: 10.16471/j.cnki.11-2822/c.2015.03.011

$\mathrm{Fu}, \mathrm{T}$. (2016). Research on the interaction mechanism and adaptation effect of human resource development and industrial transformation and upgrading--Based on China's 2010-2015 data. Hubei Social Sciences, 6, 62-70. Doi: 10.13660/j.cnki.42$1112 / c .013623$

Zheng, Y. (2017). Human capital agglomeration, spatial spillover, and industrial structure transformation and upgrading: a regional comparative analysis based on spatial filtering models. Exploration of Economic Issues, 12, 157-164. Doi: CNKI:SUN:JJWS.0.2017-12018.

Chen, C. Y., Han, Z. X., Li, X. G. (2019). Research on the impact of human capital agglomeration and spatial spillover on industrial structure upgrading: an empirical analysis based on the spatial Dubin model. Management Modernization, 39(3), 44-48. Doi: 10.19634/j.cnki.11-1403/c.2019.03.011

Kuchinke, P. K. (2003). Comparing National Systems of Human Resource Development: Role and Function of Post-baccalaureate HRD Courses of Study in the UK and US. Human Resource Development International, 6(3), 285-299. Doi: 10.1080/13678860210136071

Aryanto, R., Fontana, A., Afiff, A. Z. (2015). Strategic Human Resource Management, Innovation Capability and Performance: An Empirical Study in Indonesia Software Industry. Procedia - Social and Behavioral Sciences, 211, 874-879. Doi: 10.1016/j.sbspro.2015.11.115

Jain, S., Mittal, A., Sonwalkar, J. (2018). Human Resource Development Strategies in Indian Telecommunication Industry with Special Reference to Bharti Airtel Limited-An Empirical Study. LBS Journal of Management \& Research, 16(1), 28-34. Doi: 10.5958/0974-1852.2018.00004.4

Agus, U., Yosephine, A. Y. (2018). Human Resource Development Strategy Model: a Case Study on Small and Medium Laweyan Batik Industry in Surakarta. Journal of Economics, Business \& Accountancy, 21(2),151-158. Doi: 10.14414/jebav.v21i2.1436 
Schaupp, M. (2021). Understanding the evolution of the forms of carrying out human resource development. Human Resource Development International, 24(3), 262-278. Doi: 10.1080/13678868.2020.1818528

Huang, J. Q. (2020). Research on the changes and innovation of rural human resource development policies. Agricultural Technology and Economy, 10, 145. Doi: 10.13246/j.cnki.jae.2020.10.011

Zhao, S. M., Wei, D. X., Zhang, M. (2021). The Realistic Dilemma and Path Thinking of Human Resources Development in Hainan Free Trade Port. Journal of Hainan University (Humanities and Social Sciences Edition), 39(02), 55-62. Doi: 10.15886/j.cnki.hnus.20210301.001

Xiao, X. Z., Zhao, Z. B., Li, Y. (2020). Research on the development of rural human resources in the post-poverty era--Take Z Township, G City, S Province as an example. Journal of Sichuan University of Light Chemical Technology (Social Science Edition), 35(06), 3753. Doi: CNKI:SUN:ZGSG.0.2020-06-004

$\mathrm{Xu}, \mathrm{X}$. H. (2021). Research on the Human Resources Development Strategy of Chongqing's Intelligent Industry--Based on the Perspective of Industrial Transformation and Upgrading. Papermaking Equipment and Materials, 50(02), 15-16+23. Doi: CNKI:SUN:FLZZ.0.2021-02-007. 